\title{
Specific Labeling of Mitochondria of Chlamydomonas with Cationic Helicene Fluorophores
}

\author{
Christoph Bauer, ${ }^{a}$ Romain Duwald, ${ }^{\mathrm{b}}$ Geraldine Maria Labrador, ${ }^{\mathrm{b}}$ Simon Pascal,, $\mathrm{b}$ Pau \\ Moneva Lorente, ${ }^{\mathrm{b}}$ Johann Bosson, ${ }^{\mathrm{b}}$ Jérôme Lacour*b and Jean-David Rochaix*c \\ ${ }^{a}$ Bioimaging Center, University of Geneva, Quai Ernest Ansermet 30, 1211 Geneva 4, Switzerland \\ ${ }^{b}$ Department of Organic Chemistry, University of Geneva, quai Ernest Ansermet 30, CH-1211 Geneva 4, \\ Switzerland \\ E-mail: Jerome.Lacour@unige.ch
}

${ }^{c}$ Departments of Molecular Biology and Plant Biology, University of Geneva, Quai Ernest Ansermet 30, 1211 Geneva 4, Switzerland

E-mail: Jean-David.Rochaix@unige.ch
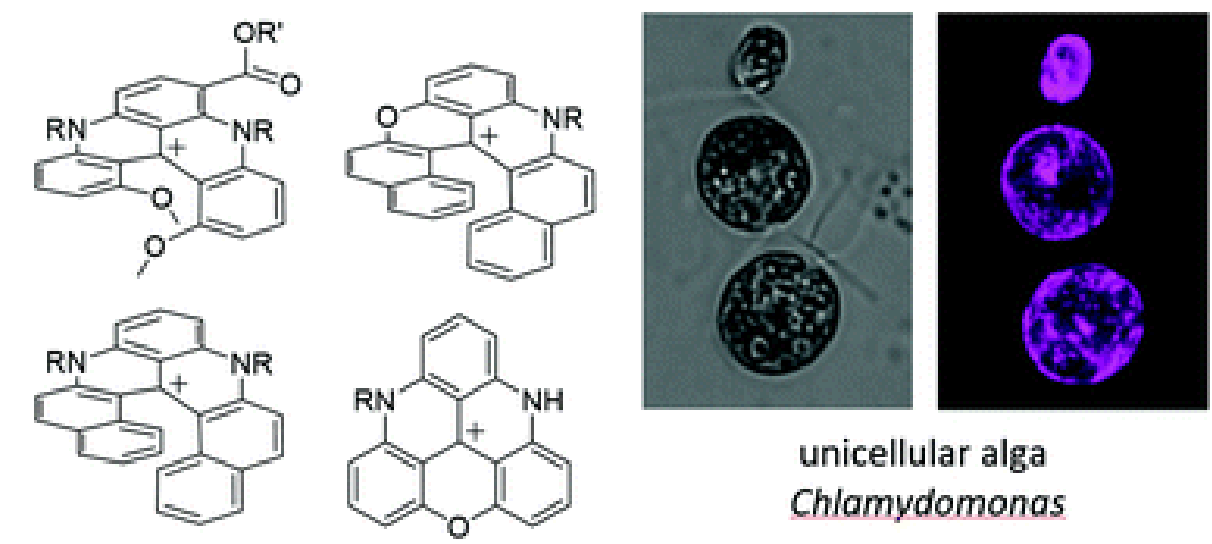

unicellular alga Chlamydomonas

\section{ABSTRACT}

Twelve cationic helicenes and one triangulene were tested for the specific labeling of mitochondria from algal cells. Octyl ester derivative $\mathbf{5}$ readily penetrates algal cells and gives rise to clear fluorescence patterns when it is used at concentrations in the $\mu \mathrm{M}$ range. Under these conditions, cell structures are well preserved and cell survival is not compromised. Cationic helicene compounds such as $\mathbf{5}$ provide new useful tools for examining the mitochondrial network and its dynamics including fission and fusion events.

Electronic supplementary information (ESI) available: Synthetic protocols, analyses, optical properties. See DOI: $10.1039 /$ c7ob02906c 


\section{Introduction}

Fluorophores have been widely used for visualizing specific subcellular structures with high spatial and temporal resolution in living cells. 1 Both fluorescent proteins and chemical dyes coupled to proteins have provided robust tools for studying the localization and dynamics of a large set of proteins. $\frac{2}{-}$ In addition, specific dyes have been developed for the labeling of specific organelles. ${ }^{3}$ As an example, the Mitotracker dyes are targeted specifically to mitochondria and can be used to follow mitochondrial fusion and fission events. Some of these Mitotracker dyes require an electrochemical potential across the mitochondrial envelope to enter these organelles while others are taken up in the absence of such a potential. Thus these dyes provide important information on the energetic state of mitochondria. They have been used extensively in animal and plant cells but less in algal cells. Although Mitotracker dyes have been used successfully to monitor mitochondrial fusion in cells of the green unicellular alga Chlamydomonas reinhardtii, ${ }^{4}$ in our hands they gave rise to variable results. Other dyes specific for mitochondria in Chlamydomonas include

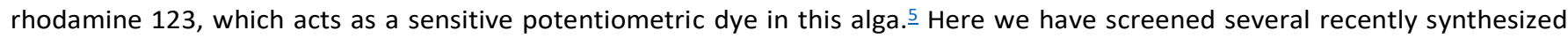
cationic dyes, which are potential candidates for specifically staining cellular organelles - and late endosomes and mitochondria in particular. $\underline{6}$ This study concerns the use of these fluorophores, and others, for labelling mitochondria in algal cells.

\section{Results and discussion}

We tested twelve cationic helicenes and one triangulene compound (Fig. 1). $\stackrel{?}{ }$ Diaza [4] helicenes 1-7 were prepared in two to five steps from 1,3-dimethoxybenzene. $\frac{8}{\text { Azaoxa 8-10 and diaza 11-12 [6] }}$ [1)licenes were prepared in six steps from 2methoxynaphthalene using a single common advanced intermediate in a highly convergent process. 9 Diazaoxa triangulene $\mathbf{1 3}$ was also prepared from 1,3-dimethoxybenzene in four steps. $\underline{\underline{6 a}}$ Some of the helicenes can be isolated as single enantiomers in gramscale but, for this study, these compounds were used as racemates. $\underline{10}$ Details are provided in the Materials and methods section.

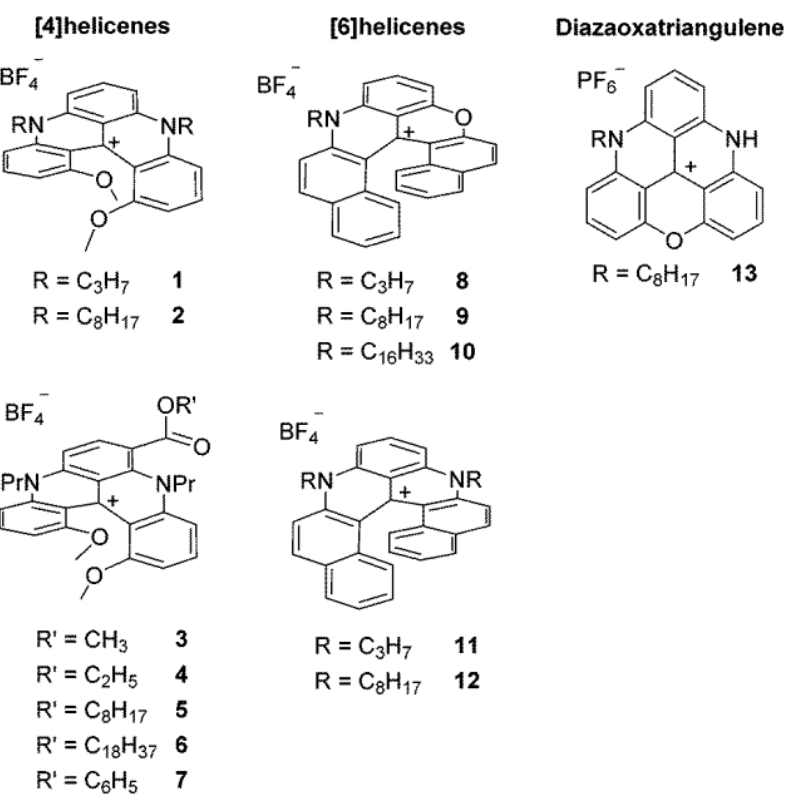

Fig. 1 Structure of cationic helicene and triangulene fluorophores 1-13.

They display absorption and fluorescence within the transparency window of biological media $\frac{8 c, 11}{1}$ and have proven to act as efficient probes for bio-imaging, $\underline{6 b, 12}$ binding selectively DNA $\underline{13}$ or behaving as chiroptical switches. $\underline{14}$ Moreover, their significant Stokes shifts, varying from 1090 to $1580 \mathrm{~cm}^{-1}$ (for 11 and 5, respectively), allow one to perform bio-imaging experiments with high signal to noise ratio (Fig. 2). For labeling subcellular structures of Chlamydomonas cells, we used a Leica confocal SP 5 microscope with tunable fluorescence excitation and emission wavelengths. Cells of Chlamydomonas in exponential growth phase were incubated for 10-20 min with these compounds. The absorption and fluorescence emission spectra of some of these helicenes are shown in Fig. 2; compounds 1, 5, 10, 11 and $\mathbf{1 3}$ were selected as representative examples. For the detection of fluorescence signals, we chose an excitation wavelength at $550 \mathrm{~nm}$ and measured fluorescence emission from 580 to $620 \mathrm{~nm}$ to minimize in terference with the endogenous chlorophyll fluorescence. 


\section{A}

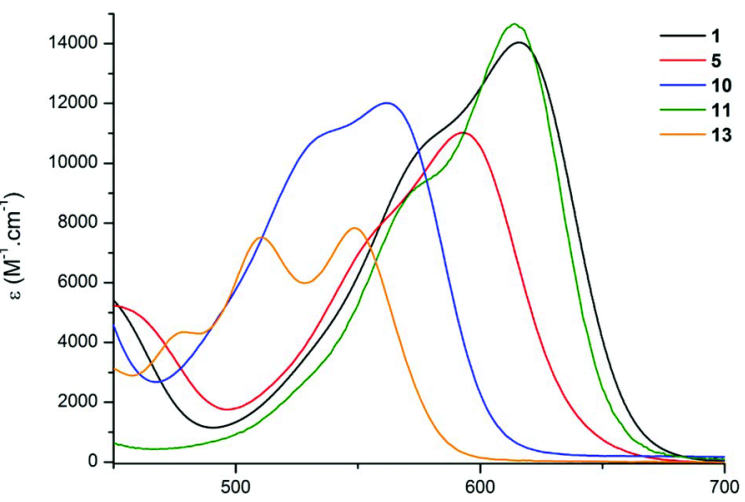

B

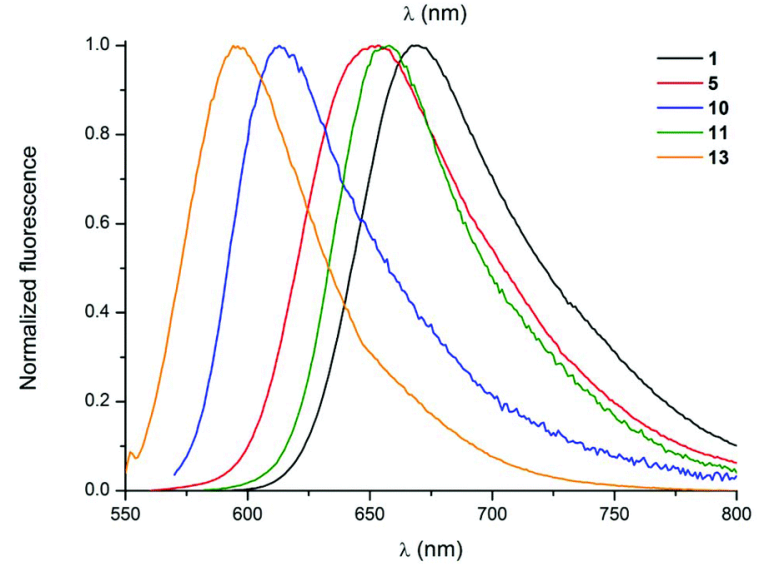

Fig. 2 Absorption (A) and fluorescence (B) spectra of $1\left(\lambda_{\mathrm{abs}}=616 \mathrm{~nm}, \lambda_{\mathrm{em}}=667 \mathrm{~nm}\right.$ Stokes shift: $\left.1240 \mathrm{~cm}^{-1}, 51 \mathrm{~nm}\right), 5\left(\lambda_{\mathrm{abs}}=593\right.$ $\mathrm{nm}, \lambda_{\mathrm{em}}=653 \mathrm{~nm}$, Stokes shift: $\left.1580 \mathrm{~cm}^{-1}, 60 \mathrm{~nm}\right), 10\left(\lambda_{\mathrm{abs}}=562 \mathrm{~nm}, \lambda_{\mathrm{em}}=613 \mathrm{~nm}\right.$, Stokes shift: $\left.1480 \mathrm{~cm}^{-1}, 51 \mathrm{~nm}\right), 11\left(\lambda_{\mathrm{abs}}=614\right.$ $\mathrm{nm}, \lambda_{\mathrm{em}}=658 \mathrm{~nm}$, Stokes shift: $\left.1090 \mathrm{~cm}^{-1}, 44 \mathrm{~nm}\right)$ and $13\left(\lambda_{\mathrm{abs}}=549 \mathrm{~nm}, \lambda_{\mathrm{em}}=594 \mathrm{~nm}\right.$, Stokes shift: $\left.1380 \mathrm{~cm}^{-1}, 45 \mathrm{~nm}\right)$.

Several of the compounds tested gave rise to specific fluorescence signals (Table 1). Chlorophyll autofluorescence was measured with excitation at $470 \mathrm{~nm}$ and fluorescence emission from 650 to $700 \mathrm{~nm}$. Of the thirteen compounds tested, five gave rise to a specific signal (1, 2, 4, 5 and 10). Compounds 5 and 10 gave the strongest response (Table 1). In particular, we noticed that extension of the ester-C8 chain of $\mathbf{5}$ to C18 in compound $\mathbf{6}$ led to a drastic decrease of staining. This is in sharp contrast to what has been observed for the labelling of mitochondria with HeLa, U87MG and PC 3 cell lines. $\underline{6 b}$ We chose compounds 4 and 5 (Fig. 1 ) for further experiments and used them at a concentration of $1 \mu \mathrm{M}$. Under these conditions, the fluorescence signal can be readily detected, the cellular structure is well preserved and cell survival is not compromised. To identify the subcellular structures labeled by these fluorophores, we used several reporter lines expressing proteins of known cellular location fused to Yellow Fluorescent Protein (YFP). $\frac{15}{1}$ These lines include proteins of the cytoplasm, nucleus, endoplasmic reticulum, mitochondria and chloroplast. YFP fluorescence was detected using excitation at $510 \mathrm{~nm}$ and fluorescence emission between $520 \mathrm{~nm}$ and $545 \mathrm{~nm}$. Comparison of the fluorescence signals obtained with YFP fused to the mitochondrial protein CAH4 (carbonic anhydrase) and helicenes $\mathbf{4}$ and $\mathbf{5}$

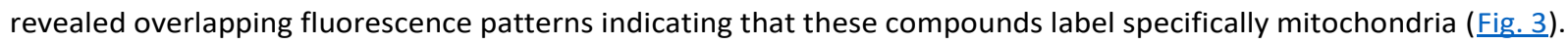



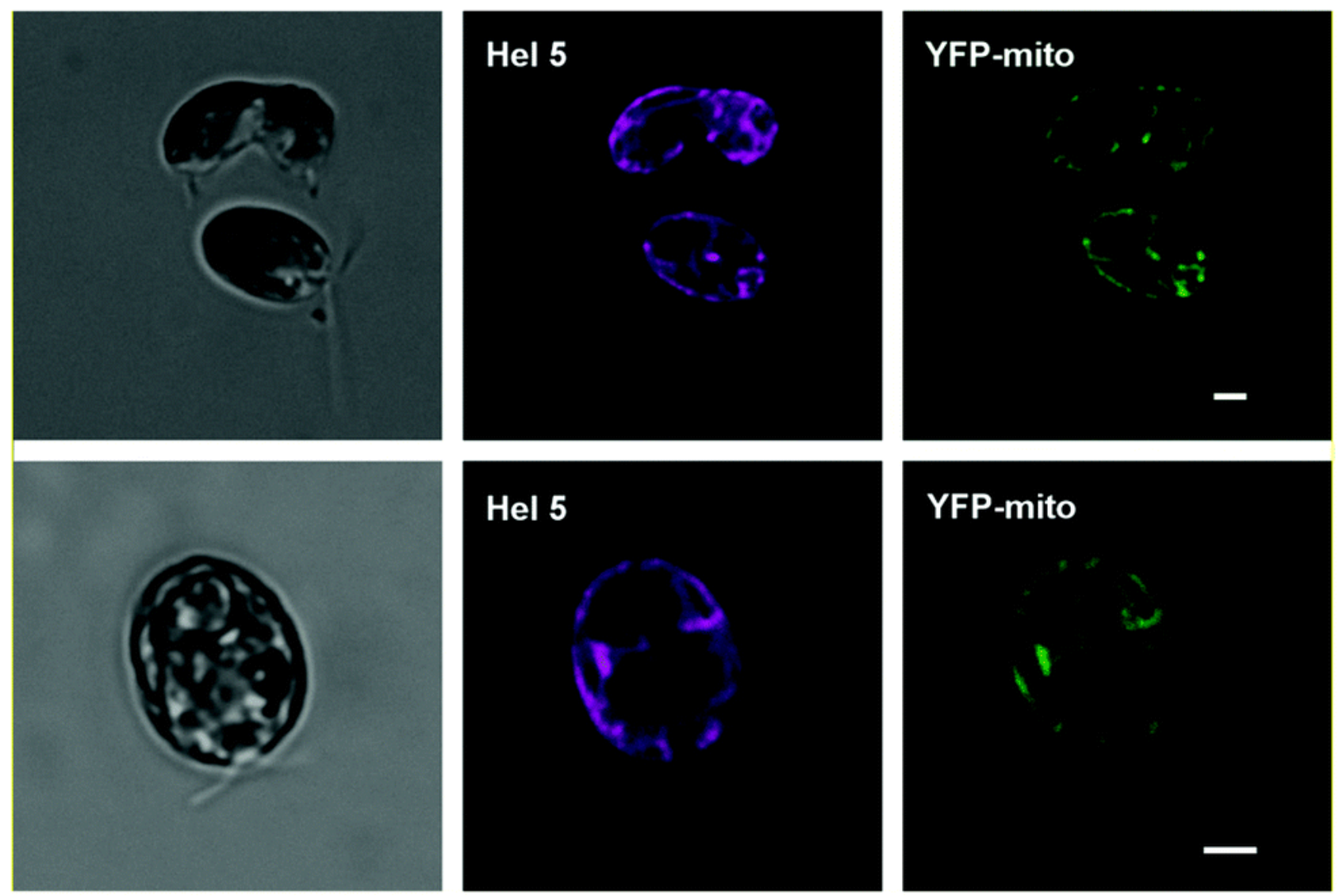

Fig. 3 Helicene 5 labels mitochondria. Cells of Chlamydomonas containing Mit-YFP (YFP-mitochondria) were treated with $1 \mu \mathrm{M}$ Helicene $\mathbf{5}$ and immobilized on glass slides treated with poly l-lysine. They were examined by phase contrast (left column, grey) and fluorescence microscopy on a Leica confocal SP 5 microscope with the following settings: Helicene $\mathbf{5}$ fluorescence excitation at $550 \mathrm{~nm}$ and fluorescence emission from 580-620 nm (labelled Hel 5, middle column, magenta); YFP-mitochondria, fluorescence excitation at $510 \mathrm{~nm}$ and fluorescence emission from 520-545 nm (labelled YFP-mito, right column, green). Bars $2 \mu \mathrm{m}$.

Table 1 Excitation emission conditions

\begin{tabular}{|l|l||l||}
\hline Target & Excitation wavelength & Emission wavelength window \\
\hline \hline Fluorophores 1-13 & $550 \mathrm{~nm}$ & $580-620 \mathrm{~nm}$ \\
\hline \hline YFP & $510 \mathrm{~nm}$ & $520-545 \mathrm{~nm}$ \\
\hline Mitotracker deep red & $620 \mathrm{~nm}$ & $655-680 \mathrm{~nm}$ \\
\hline
\end{tabular}

Comparison with the fluorescence obtained with the Mitotracker dye Deep Red further confirmed the mitochondrial location of 5 (Fig. 4). The similarities of fluorescence patterns of $\mathbf{5}$ with those of mitochondrial protein CAH4 were striking and seemed even better correlated than those obtained with the Mitotracker dye. 

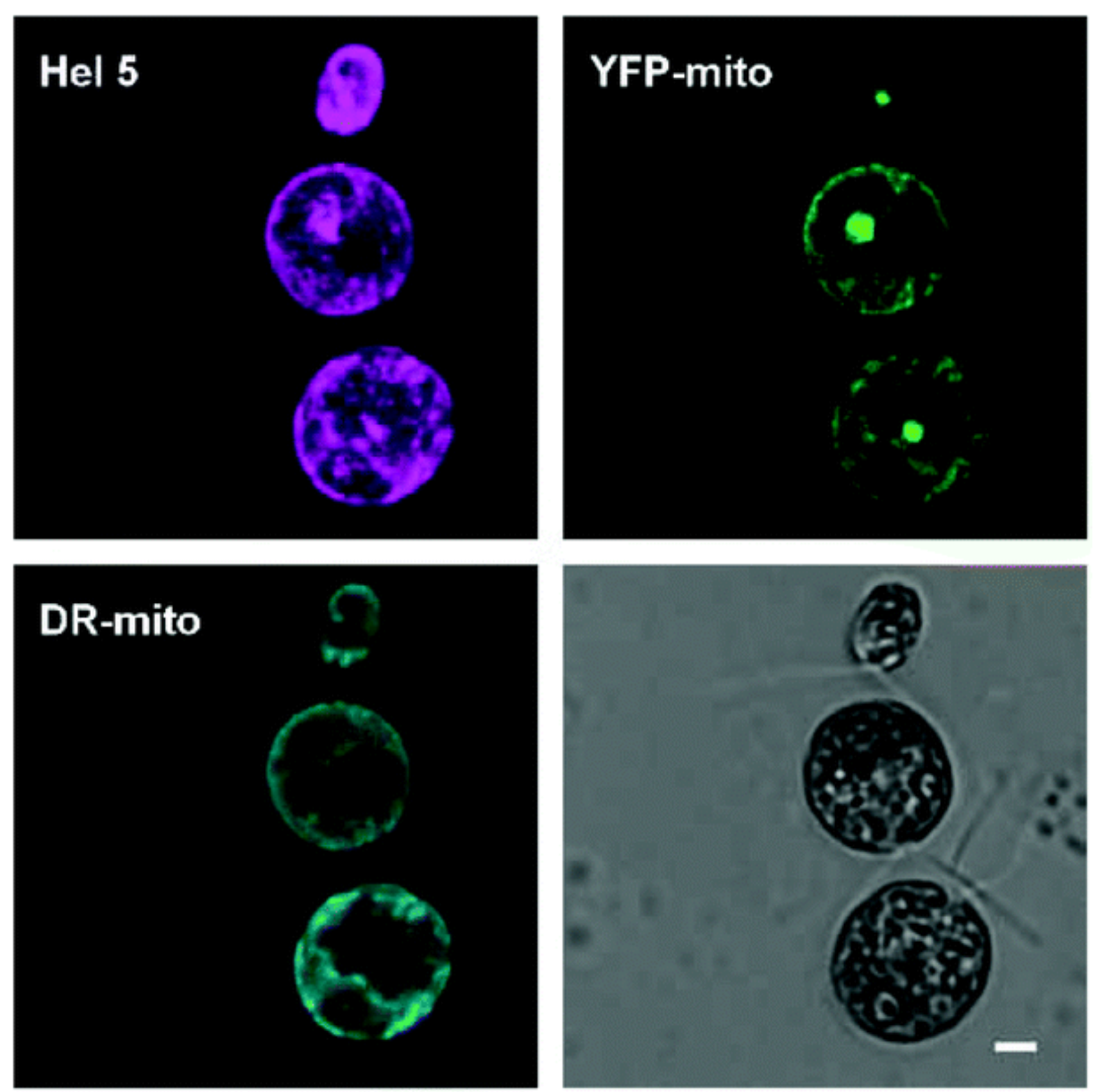

Fig. 4 Fluorescence patterns of Helicene $\mathbf{5}$ and Mitotracker Deep Red are similar. Cells of Chlamydomonas containing YFPmitochondria (labelled YFP-mito, upper right, green) were treated with $1 \mu \mathrm{M}$ Helicene $\mathbf{5}$ (labelled Hel 5, upper left, magenta) and $1 \mu \mathrm{M}$ Mitotracker Deep Red (labelled DR-mito, lower left, cyan) and immobilized on glass slides treated with poly I-lysine. Fluorescence settings were as in Fig. 3 and for Mitotracker Deep Red: fluorescence excitation at $620 \mathrm{~nm}$ and fluorescence emission from 655 to $680 \mathrm{~nm}$. Bar $2 \mu \mathrm{m}$.

To further test the specificity of mitochondrial labeling with $\mathbf{5}$, we compared its fluorescence patterns with those obtained with two YFP-tagged chloroplast proteins, the stromal protein Rubisco and Tic20, a component of the protein translocon of the inner chloroplast membrane. As seen in Fig. 5 , the fluorescence patterns obtained with these proteins were very different from those of 5 indicating that this compound does not bind or enter chloroplasts. 
A
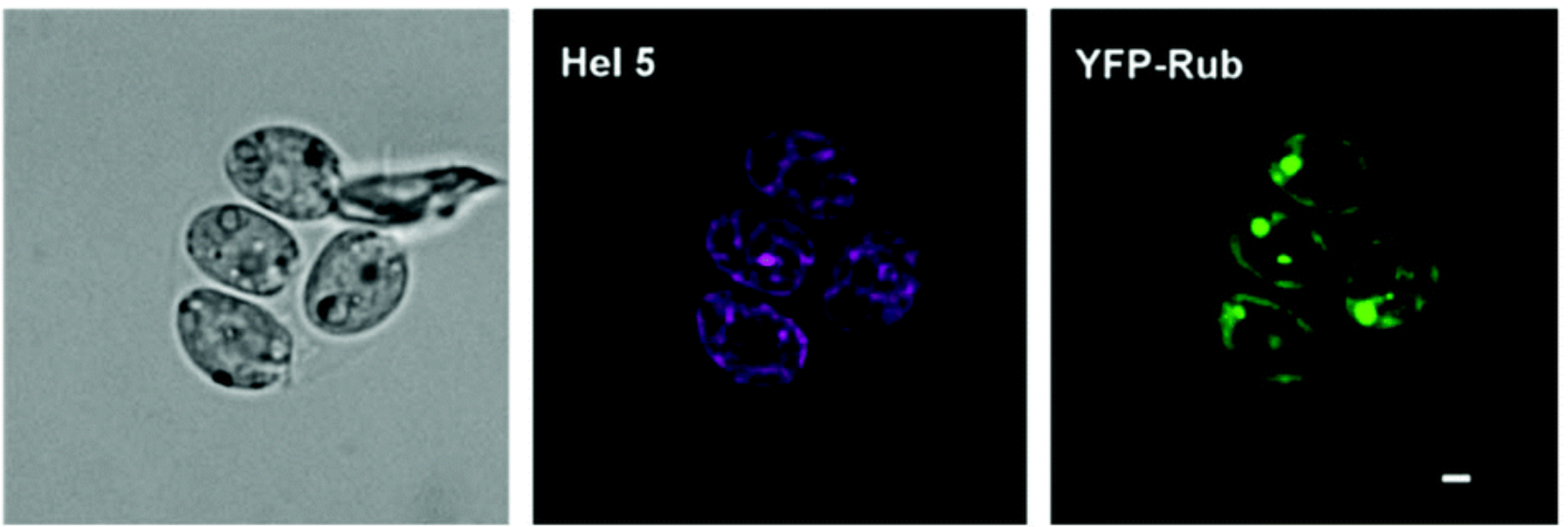

\section{B}
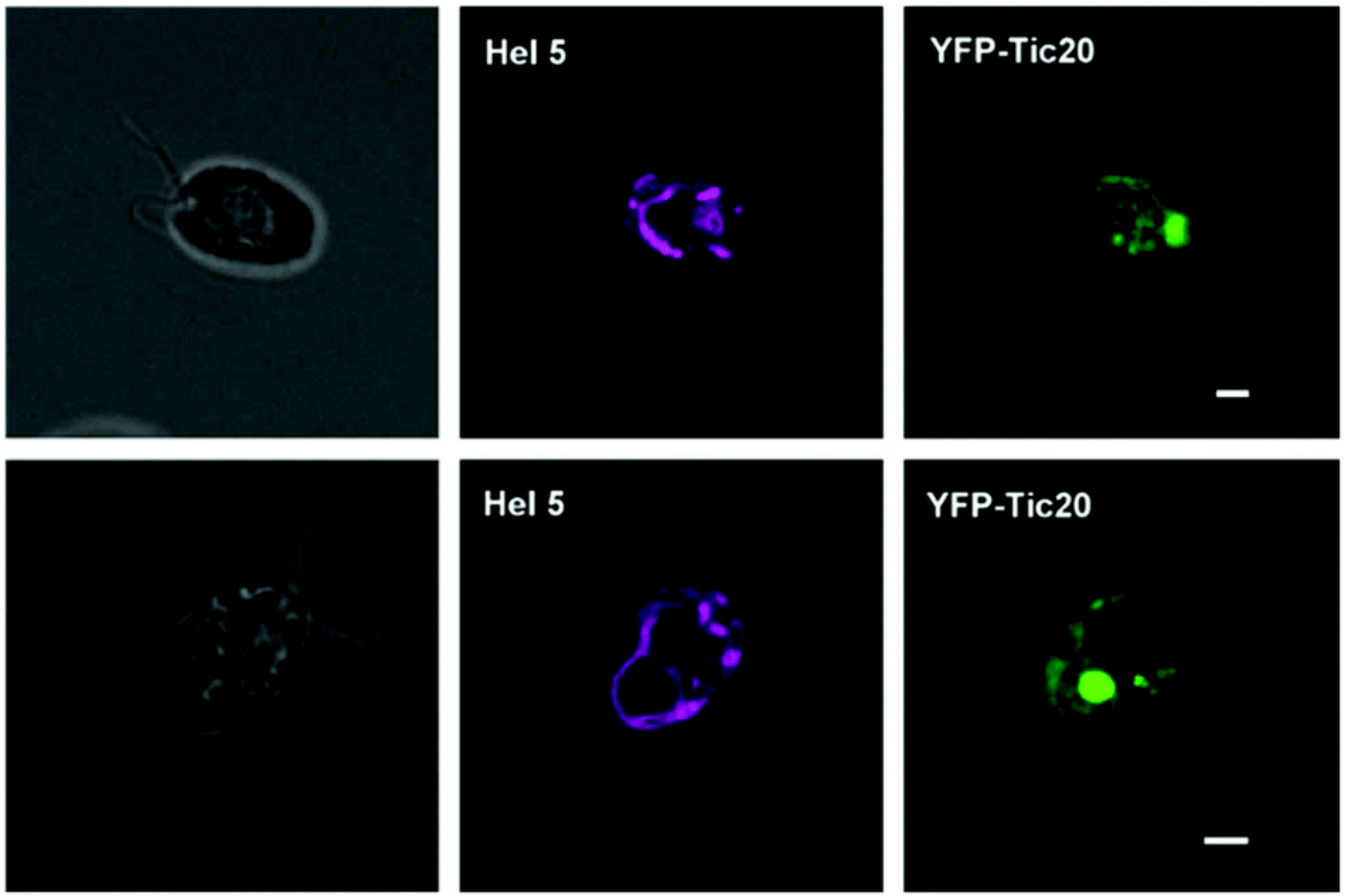

Fig. 5 Cell fluorescence patterns of Helicene $\mathbf{5}$ are different from those of chloroplast proteins. A. Comparison of fluorescence of Helicene 5 (labelled Hel 5, middle, magenta) with the small subunit of Rubisco fused to YFP (labelled YFP-Rub, right, green) (chloroplast stromal protein). B. Comparison of fluorescence of Helicene $\mathbf{5}$ (labelled Hel $\mathbf{5}$, middle column, magenta) with Tic20YFP (labelled YFP-Tic20, right column, green) (chloroplast inner envelope protein). Bars $2 \mu \mathrm{m}$.

To examine whether the entrance of 5 into mitochondria requires an electrochemical potential, cells were treated with $5 \mu \mathrm{M}$ FCCP to collapse this gradient. Under these conditions, no fluorescence was detected indicating that this fluorophore enters mitochondria only in the presence of an electrochemical gradient (Fig. 6A). Treatment of the cells with myxothiazol, an inhibitor of the bc1 complex and hence of the respiratory electron transfer chain did not significantly affect the fluorescence of $\mathbf{5}$ as compared to untreated cells (Fig. 6B). This result was expected since, under these conditions, the ATP synthase acts as an ATPase and generates an electrochemical gradient by pumping protons into the mitochondrial matrix. 

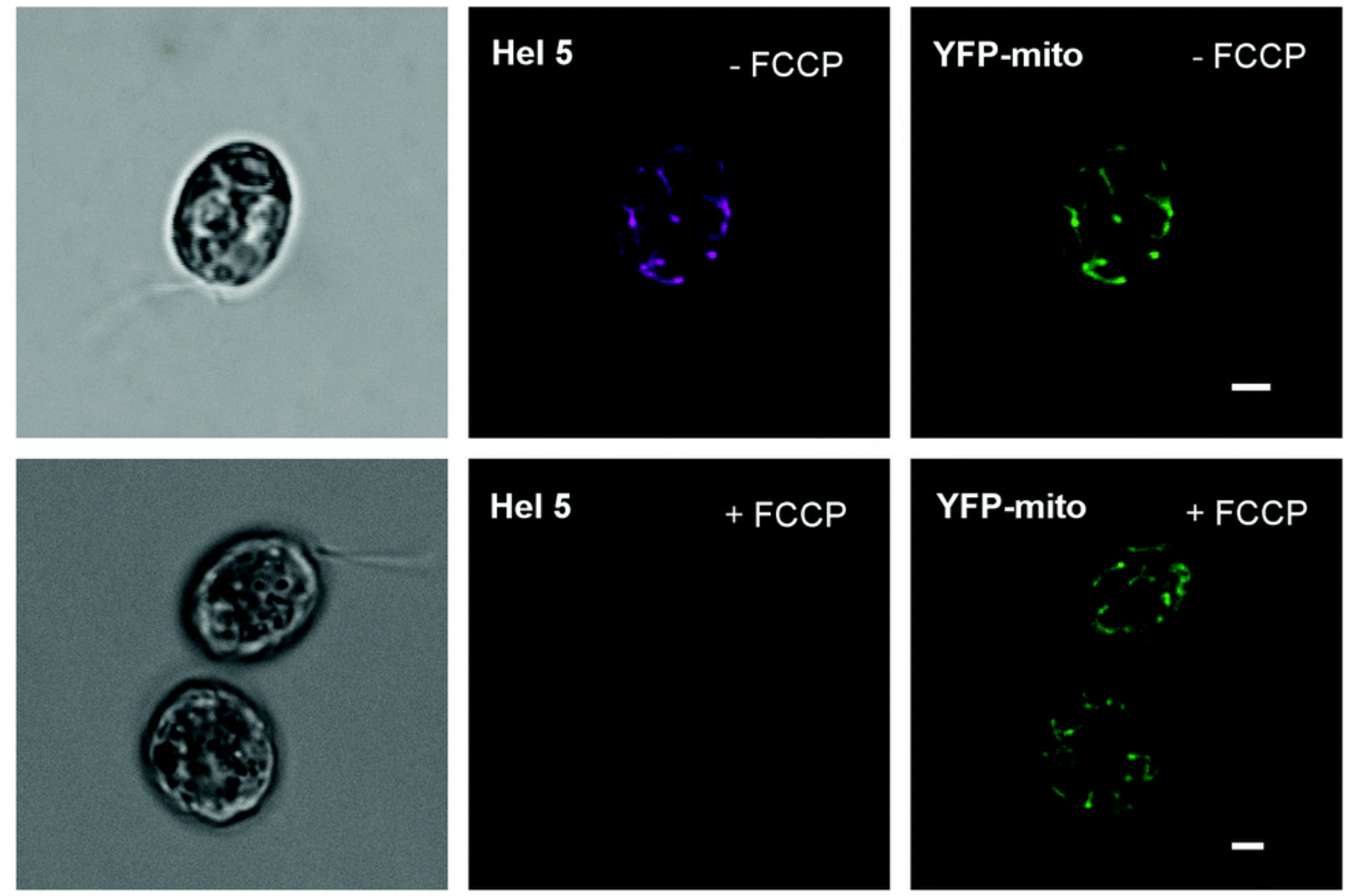

B
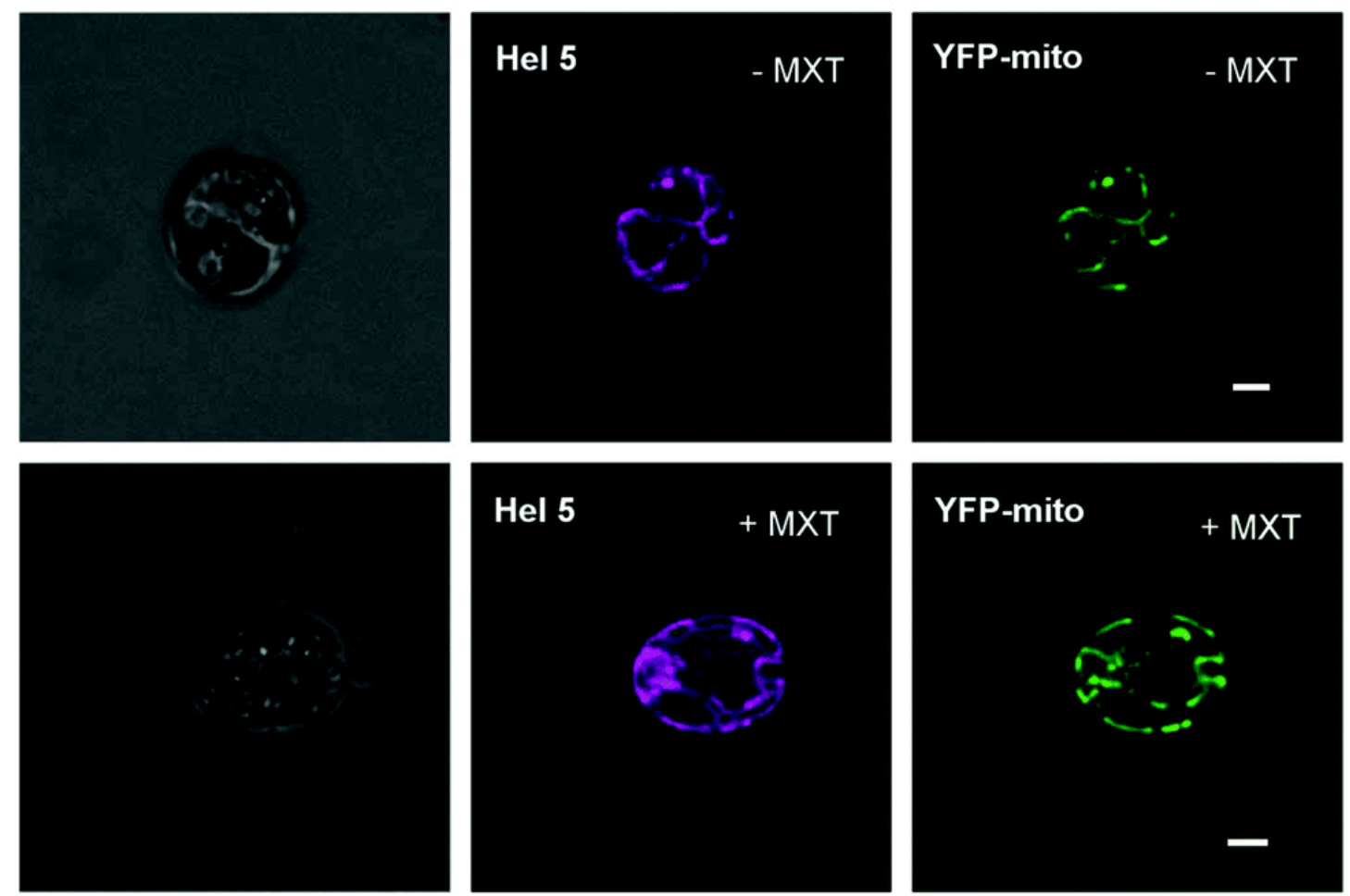

Fig. 6 Fluorescence of Helicene $\mathbf{5}$ of Chlamydomonas cells requires an electrochemical potential across the mitochondrial membrane. A. Chlamydomonas cells containing MitYFP were treated with 5 HM FCCP (labelled + FCCP, lower row) or without (upper row, labelled - FCCP). Whereas mitochondrial YFP staining (labelled YFP-mito, right column, green) stays intact, the Helicene 5 staining (labelled Hel 5, middle column, magenta) disappears upon FCCP treatment (lower row, middle). B. Cells were treated with $5 \mu \mathrm{M}$ myxothiazol (lower row, labelled + MXT) or without (upper row, labelled - MXT). Mitochondrial YFP staining (labelled YFP-mito, right column, green) as well as Helicene $\mathbf{5}$ staining (labelled Hel $\mathbf{5}$, middle column, magenta) are undisturbed by myxothiazol treatment. Bars $2 \mu \mathrm{m}$. 


\section{Conclusions}

We have shown that a small number of cationic helicene and triangulene compounds can be used for specifically labeling mitochondria from algal cells. These compounds are remarkably different from those targeting mitochondria in HeLA, PC3 or U87MG cancer cell lines. $\underline{6 b}$ It is most likely that they can be utilized for the same purpose in other organisms. Helicene 5 readily penetrates algal cell and gives rise to clear fluorescence patterns when it is used at concentrations in the $\mu \mathrm{M}$ range. Under these conditions cell structures are well preserved and cell survival is not compromised. Thus, helicene compounds provide new useful tools for examining the mitochondrial network and its dynamics including fission and fusion events. Another interesting property of some of these helicenes is their chemiluminescence. $\frac{16}{\mathrm{In}} \mathrm{fact}$, the luminescence of some of these compounds can be triggered by oxidations or reductions and they could hence be potentially used to monitor the cellular redox environment. However, we were unable to detect any (bio)luminescence with the compounds tested so far.

\section{Materials and methods}

The Chlamydomonas strains used in this study were wild type $137 \mathrm{C}$, and several derivatives of cmj30 expressing proteins in the nucleus, mitochondria, chloroplast, endoplasmic reticulum, cytoplasm tagged with YFP 15 and obtained from Dr Martin Jonikas and Silvia Ramundo. Cells were grown in TAP medium with an irradiance of $60 \mu \mathrm{mol} \mathrm{m} \mathrm{m}^{-2} \mathrm{~s}^{-1}$ at $25^{\circ} \mathrm{C}$.

\section{Luminescence}

Fluorescence quantum yields in acetonitrile of cationic dyes (relative to cresyl violet $(\mathrm{MeOH}, 54 \%)$ ) were previously reported in the literature: $1(\varphi=13 \%), \mathbf{4}(\varphi=37 \%), 8(\varphi=22 \%)$ and $11(\varphi=31 \%) . \underline{.8 c, 11}$

\section{Fluorophores}

Fluorophores 1-7 were obtained in no more than four synthetic steps from tris(2,6-dimethoxy)triarylcarbenium 14. The [4] helicene scaffold was built by successive nucleophilic aromatic substitutions of MeO groups by primary amine nucleophiles ( $R=n P r, n O c t)$ at $90{ }^{\circ} \mathrm{C}$ in DMF for $1 \mathrm{~h} . \underline{8 b, 10 b}$ Access to ester derivatives 3-7 required a multi-step sequence. First, the regioselective VilsmeierHaack formylation of $\mathbf{1}$ followed by a Pinnick-Kraus oxidation led to the formation of a carboxylate derivative. $\frac{8 c}{\text { Conversion to the }}$ corresponding acyl chloride and addition of excess of alcohols yielded esters 3-7 in high yields (Scheme 1). For the preparation of triangulene 13, triarylcarbenium 14 was treated with hydrazine and then $n$-octylamine to afford non-symmetrical [4] helicene 15. 17 Heating this compound in molten pyridinium chloride led to $\mathbf{1 3}$ in $\mathbf{8 5 \%}$ yield. Azaoxa [6]helicenes $\mathbf{8 - 1 0}$ were obtained by mixing precursor 16 with an excess of primary amine in acetonitrile. 9 Higher temperature and microwave irradiation allowed the access to diaza [6]helicenes 11 and 12. 


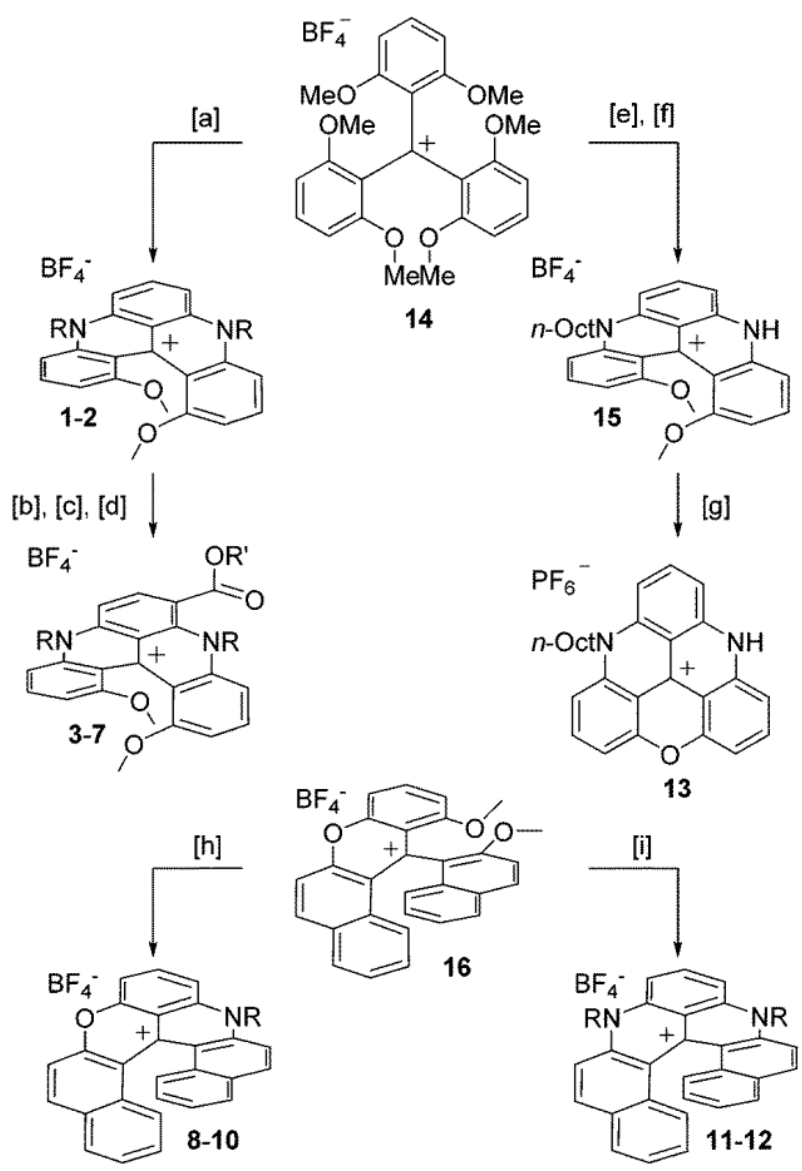

Scheme 1 Synthesis of cationic dyes. [a] $\mathrm{RNH}_{2}$ (25 equiv.), DMF, $90{ }^{\circ} \mathrm{C}, 1 \mathrm{~h}$. [b] $\mathrm{POCl}_{3}\left(24\right.$ equiv.), DMF, $90{ }^{\circ} \mathrm{C}, 8 \mathrm{~h}$. [c] $\mathrm{NaH}_{2} \mathrm{PO}_{4}(1$ equiv.), $\mathrm{H}_{2} \mathrm{O}_{2}, \mathrm{MeCN}, 60{ }^{\circ} \mathrm{C}, 1 \mathrm{~h}$. [d] (i) $\mathrm{SOCl}_{2}$ (6 equiv.), $\mathrm{CH}_{2} \mathrm{Cl}_{2}, 25^{\circ} \mathrm{C}, 10 \mathrm{~min}$; (ii) $\mathrm{R}^{\prime} \mathrm{OH},\left(5-15\right.$ equiv.), $25^{\circ} \mathrm{C}, 10-15 \mathrm{~min}$. [e] $\mathrm{H}_{2} \mathrm{~N}-$ $\mathrm{NH}_{2} \cdot \mathrm{H}_{2} \mathrm{O}$ (2.5 equiv.), MeCN, $25^{\circ} \mathrm{C}, 30 \mathrm{~min}$. [f] $n$-OctNH 2 (25 equiv.), DMF, $90{ }^{\circ} \mathrm{C}, 16 \mathrm{~h}$. [g] Pyr $\cdot \mathrm{HCl}, 160{ }^{\circ} \mathrm{C}, 38 \mathrm{~h}$. [h] RNH $2, \mathrm{MeCN}^{\circ}$ 70-90 ${ }^{\circ} \mathrm{C}$. [i] $\mathrm{RNH}_{2}, \mathrm{NMP}, \mathrm{MW}, 170^{\circ} \mathrm{C}, 10 \mathrm{~min}$.

The fluorophores were prepared in $10 \mathrm{mM}$ stock solutions in DMSO. They were first tested on Chlamydomonas cells at a concentration of $10 \mu \mathrm{M}$ to check whether they could enter the cells and finally used at a concentration of $1 \mu \mathrm{M}$.

\section{Confocal microscopy and image analysis}

For labeling, cells were mixed with their respective dyes diluted in cell culture medium and incubated for 10 to 20 minutes. Before imaging cells were immobilized on poly-l lysine coated slides. Imaging was then performed with a Leica SP5 confocal microscope equipped with a tunable white light laser (WLL) allowing for free choice of excitation wavelength (within a window ranging from 470 to $670 \mathrm{~nm}$ ). AOBS (acusto-optical tunable filter) and spectral detection allowed additionally to freely choose appropriate detection windows. See Table 1 for excitation emission conditions used.

Fluorescence emission was detected using a 63x Plan-Apo oil immersion objective (NA 1.4) and newest generation hybrid (HyD) detectors with the pinhole closed to one airy unit. Cells were zoomed to obtain an effective pixel size of 50 to $80 \mathrm{~nm}$ fulfilling Nyquist criterion. For visualization purposes, helicene fluorophore emission is shown in purple, YFP emission in green and mitotracker deep red emission in cyan.

\section{Conflicts of interest}

There are no conflicts to declare.

\section{Acknowledgements}

We would like to acknowledge the Mass Spectrometry platform at the University of Geneva for the mass spectroscopy analysis. We thank the University of Geneva and the Swiss National Science Foundation for funding. 


\section{Notes and references}

1. Z. Guo , S. Park , J. Yoon and I. Shin , Chem. Soc. Rev., 2014, 43, $16-29$.

2. Q. Yan and M. P. Bruchez, Cell Tissue Res., 2015, 360, 179-194.

3. Z. Xu and L. Xu , Chem. Commun., 2016, 52, $1094-1119$.

4. D. Scholz and B. Westermann , Eur. J. Cell Biol., 2013, 92 , $80-86$.

5. M. R. Brickley, E. Lawrie , V. Weise, C. Hawes and A. H. Cobb , Pest Manage. Sci., 2012, 68,580 - 586.

6. (a) A. Wallabregue, D. Moreau, P. Sherin, P. Moneva Lorente , Z. Jarolímová , E. Bakker , E. Vauthey , J. Gruenberg and J. Lacour , J. Am. Chem. Soc., 2016, 139 , 1752 -1755. (b) A. Babič , S. Pascal, R. Duwald, D. Moreau, J. Lacour and E. Allémann , Adv. Funct. Mater., 2017, $27,1701839$.

7. J. Bosson, J. Gouin and J. Lacour, Chem. Soc. Rev., 2014, 43, $2824-2840$.

8. (a) B. W. Laursen and F. C. Krebs, Angew. Chem., Int. Ed., 2000, 39 , 3432 -3434. (b) C. Herse, D. Bas, F. C. Krebs, T. Bürgi , J. Weber , T. Wesolowski, B. W. Laursen and J. Lacour, Angew. Chem., Int. Ed., 2003, 42 , 3162 -3166. (c) I. Hernández Delgado, S. Pascal , A. Wallabregue , R. Duwald , C. Besnard , L. Guénée , C. Nançoz , E. Vauthey , R. C. Tovar , J. L. Lunkley, G. Muller and J. Lacour, Chem. Sci., 2016, $7,4685-4693$.

9. (a) F. Torricelli , J. Bosson , C. Besnard , M. Chekini , T. Bürgi and J. Lacour , Angew. Chem., Int. Ed., 2013,52 , 1796 1800. (b) Z. Jarolímová , J. Bosson, G. M. Labrador, J. Lacour and E. Bakker, Electroanalysis, 2017, 29.

10. (a) G. Solladié , J. Hutt and A. Girardin, Synthesis, 1987, 173 -173. (b) B. Laleu , P. Mobian , C. Herse , B. W. Laursen , G. Hopfgartner , G. Bernardinelli and J. Lacour , Angew. Chem., Int. Ed., 2005, 44 , $1879-1883$. (c) B. Laleu, M. S. Machado and J. Lacour, Chem. Commun., 2006, $2786-2788$.

11. J. Bosson, G. M. Labrador, S. Pascal , F.-A. Miannay , O. Yushchenko, H. Li , L. Bouffier , N. Sojic, R. C. Tovar , G. Muller , D. Jacquemin , A. D. Laurent , B. Le Guennic , E. Vauthey and J. Lacour , Chem. - Eur. J., 2016, 22 , 18394 -18403.

12. (a) K. E. S. Phillips, T. J. Katz, S. Jockusch, A. J. Lovinger and N. J. Turro , J. Am. Chem. Soc., $2001,123,11899-11907$. (b) L. Latterini , E. Galletti , R. Passeri , A. Barbafina , L. Urbanelli , C. Emiliani , F. Elisei , F. Fontana , A. Mele and T. Caronna , J. Photochem. Photobiol., A, 2011, 222 , 307 -313. (c) O. Kel , P. Sherin, N. Mehanna, B. Laleu, J. Lacour and E. Vauthey , Photochem. Photobiol. Sci., 2012, 11 , 623 -631. (d) M. Li , L.-H. Feng , H.-Y. Lu , S. Wang and C.-F. Chen , Adv. Funct. Mater., 2014, $24,4405-4412$.

13. O. Kel , A. Fürstenberg, N. Mehanna , C. Nicolas, B. Laleu , M. Hammarson , B. Albinsson , J. Lacour and E. Vauthey , Chem. - Eur. J., 2013, $19,7173-7180$.

14. S. Pascal , C. Besnard , F. Zinna , L. Di Bari , B. Le Guennic, D. Jacquemin and J. Lacour , Org. Biomol. Chem., 2016, 14 , $4590-4594$.

15. E. S. Freeman Rosenzweig , B. Xu , L. Kuhn Cuellar, A. Martinez-Sanchez, M. Schaffer, M. Strauss , H. N. Cartwright , P. Ronceray , J. M. Plitzko , F. Förster, N. S. Wingreen , B. D. Engel , L. C. M. Mackinder and M. C. Jonikas , Cell, 2017, 171 , $148-162 . e 119$.

16. (a) H. Li , A. Wallabregue , C. Adam, G. M. Labrador, J. Bosson, L. Bouffier , J. Lacour and N. Sojic, J. Phys. Chem. C, 2017, 121 , 785 - 792. (b) H. Li , S. Voci , A. Wallabregue , C. Adam , G. M. Labrador, R. Duwald , I. Hernández Delgado, S. Pascal , J. Bosson, J. Lacour , L. Bouffier and N. Sojic, ChemElectroChem, 2017, 4, $1750-1756$. (c) C. Adam , A. Wallabregue , H. Li , J. Gouin, S. Grass, J. Bosson , L. Bouffier , J. Lacour and N. Sojic , Chem. - Eur. J., 2015, 21, $19243-19249$.

17. A. Wallabregue, P. Sherin , J. Guin , C. Besnard , E. Vauthey and J. Lacour , Eur. J. Org. Chem., 2014, $6431-6438$. 